\title{
Magnetic structural information obtained from the HiRES airborne survey of the Isle of Wight
}

\section{James C. White and David Beamish}

British Geological Survey, Keyworth, Nottingham, NG12 5GG, UK.

Corresponding author:

James C. White (jame3@bgs.ac.uk)

British Geological Survey, Keyworth, Nottingham, NG12 5GG, UK.

Tel: + +44(0) 1159363354

Fax: +44(0) 1159363437

Email: jame3@bgs.ac.uk

For submission to Proceedings of the Geologists Association, Special Issue

October 2010

Received in original form

Keywords: Airborne geophysics, magnetic anomalies, Isle of Wight, magnetic interpretation, southern UK.

Right running head: Aeromagnetic data, Isle of Wight. 


\section{Abstract}

This study summarises the structural information obtained from a modern high resolution magnetic survey over the Isle of Wight corroborated with additional information derived from existing data available over a much wider area. This new, low-altitude, survey offered the opportunity to compare the UK national baseline magnetic data set (GSGB) acquired during the late 1950s and early 1960s with a high resolution airborne geophysical survey (HiRES) data set. The low level modern survey data, covering an unusually small area for an airborne magnetic investigation, has not been systematically de-cultured for non-geological perturbations since the extent of the cultural interference made the task non-viable. However, after spectral filtering of the two data sets, a West to East trending arcuated magnetic basement feature is successfully defined and compared. Depth estimates for this basement feature are proposed and considered alongside previous estimates which placed the causative body at greater depth.

Onshore, the low gradient magnetic field, with little significant shallow magnetic structure within a thick succession of sedimentary rocks, is subjected to a range of filtering techniques that permit a preliminary interpretation of lineaments within the succession. This line work is considered in conjunction with the regional fault mapping undertaken as part of a seismic re-interpretation. 


\section{Introduction}

During the decade that followed the mid 1950s, UK national baseline magnetic (GSGB) data were acquired from a series of regional airborne surveys. National scale magnetic anomaly maps have been published from these data (British Geological Survey, 1998) and potential field images have been used to investigate the nature of the Variscan basement in the southern UK (Busby and Smith, 2001). This paper uses the High Resolution Environmental and Resource Survey (HiRES) data, acquired during September and October 2008, to update the earlier magnetic anomaly map over the Isle of Wight. The Isle of Wight lies off the southern coast of England, separated from the mainland by the Solent, and provides a neat package within which to carry out this new survey. The processing of the data is described by White et al. (2009).

The High Resolution Environmental and Resource Survey of the Isle of Wight acquired magnetic, radiometric and electromagnetic measurements and was undertaken alongside a detailed revision of the mapped geology by the British Geological Survey (BGS). The airborne survey encountered problems inherently associated with small-scale surveys over relatively non-magnetic sedimentary rocks where the dominant spectral wavelengths of the cultural interference are similar to those due to near surface geological sources.

The long wavelength component of this new data set is considered alongside that obtained from the GSGB data whilst the culturally distorted shorter wavelength component of the data is used to assess the response of a largely non-magnetic sedimentary sequence. The results are summarised as a series of magnetic lineaments within the sediments and these are presented alongside the mapped faults derived from the seismic data, a précis of which is presented in Evans et al. (2010 'this issue').

\section{Geological background}

The Isle of Wight forms part of the Wessex-Channel basin, which itself is situated on- and off-shore of central southern England (see location map of Fig. 1) and contains a thick succession of Jurassic to Cretaceous rocks. The older sedimentary basement within this basin consists of pre-Permian sediments deformed during the Variscan Orogeny (Underhill and Paterson, 1998). Subsequent to this Late Palaeozoic convergence, a period of crustal extension paved the way for significant sedimentary deposition that initiated in the Permian. The subsidence patterns at this time were defined by major en echelon, approximately E-W trending, normal faults with southerly downthrows (Chadwick, 1993). The sediments of Permian to Mid Cretaceous age were deposited during this 
period of widespread regional subsidence and extension, which lead to a series of asymmetrical graben structures separated by structural high zones. The Mid to Late Cretaceous sedimentary deposition that followed coincided with the cessation of crustal extension meaning the Late Cretaceous and Early Tertiary sediments were deposited as flat, predominantly fault-free units. Subsequent basin inversion, as a consequence of compressional tectonics, began in the Early Tertiary with the major inversion episode coinciding with the continental collision of Europe and Africa in the Miocene. Compression at this time was accommodated principally by folding and reactivation of the pre-existing normal faults, but in a reverse sense, and has led to the Isle of Wight offering a microcosm of southern England geology ideally suited to a multi-component survey of this sort.

\section{The magnetic data}

The primary characteristic of the magnetic data is the response of the magnetic basement; and in this magnetic basement context the HiRES data confirms the interpretation of the legacy data. Fig. 1 shows the UK national baseline magnetic data for an area of 160 by $136 \mathrm{~km}$ that encompasses the Isle of Wight. The typical maximum grid resolution (using a quarter-wavelength sampling criterion) that can be achieved using the GSGB data is $500 \times 500 \mathrm{~m}$ and Fig. 1 was constructed using a minimum curvature gridding interval at this resolution. The coordinate system used throughout is the British National Grid (BNG). The HiRES study region marks the northerly limit of a series of E-W trending short wavelength anomalies that define the inner zone of the European Variscides. The anomalies have been interpreted as discrete volcanic bodies, of significant length along strike, within the upper region of the Variscan basement by Busby and Smith (2001). Busby and Smith (2001) estimate the depth to the tops of these bodies at between 2 and $5 \mathrm{~km}$.

Overlying the magnetic basement, the sedimentary sequence is primarily non-magnetic. The scope of the present study is to generate an interpretation that delineates faults in the sedimentary package. These subtle faults appear at the bounds of detection available to the HiRES survey and were not resolved by the original UK national baseline magnetic data.

The HiRES survey design was optimised for electromagnetic and radiometric acquisition (Beamish and White, 2010a 'this issue'; Beamish and White, 2010b 'this issue') although the Joint AirborneGeoscience Capability (JAC) 'three-in-one' measurement system (Hautaniemi et al., 2005) includes a magnetic component that is the subject of this paper. The acquisition parameters and processing procedures applied to the Isle of Wight HiRES survey are described in Beamish and Cuss (2009) and White et al. (2009). A review of the Isle of Wight HiRES survey parameters are provided in Beamish 
and White (2010b 'this issue'), but it is worth repeating that the data were collected with $200 \mathrm{~m}$ line magnetic field is about every $5 \mathrm{~m}$. This is substantially better resolution than earlier surveys. The Total Magnetic Intensity (TMI) data are presented as a superimposed anomaly field related to a model of the International Geomagnetic Reference Field (IGRF) determined at a date appropriate to the acquisition and processing of the data. The national baseline (GSGB) magnetic data is referred to IGRF 1990 whilst the HiRES data is referred to IGRF 2009. The TMI anomaly field for the HiRES data is shown in Fig. 2.

Isolated, high-wavenumber perturbations in the data, which reflect the significant levels of cultural interference that exists across onshore UK, are a feature of the low level HiRES magnetic data. Magnetic deculturing techniques that combine manual and semi-automatic procedures have previously been examined and applied to some of the HiRES data sets (Lahti et al. 2007). Here we adopt a simplified approach for locating and then systematically reducing the amplitude of cultural artefacts, that is appropriate in the context of the largely non-magnetic sedimentary cover sequence found across the survey area. The technique employs the analytical signal transform to detect and remove isolated and clustered gradients corresponding to cultural interference. The analytical signal (AS) is defined, when applied to gridded data sets, as:

$$
A S=\sqrt{\left(\frac{\partial T}{\partial x}\right)^{2}+\left(\frac{\partial T}{\partial y}\right)^{2}+\left(\frac{\partial T}{\partial z}\right)^{2}}
$$

where $T$ is the magnetic field and the AS can be seen to be the total gradient calculated from derivatives in all three orthogonal directions. Fig. 3 shows the AS of the HiRES IOW data as a 3D perspective view. As is very evident, the significant peaks in the AS of the onshore IOW magnetic data define only cultural artefacts. The amplitudes of these gradients far exceed those of the geological contributions. By eliminating the TMI anomaly field where the AS grid exceeds a maximum value of $0.03 \mathrm{nT} \mathrm{m}^{-1}$, shown in blue in Fig. 3, and interpolating through the resulting data gaps reveals a smoother magnetic field which still maintains the longer wavelength, residual geological signal in the data.

The 'de-cultured' TMI data from the HiRES survey is shown in Fig. 4 and the nature of the resulting field can be compared with the original data in Fig. 2. Whilst the data have not been systematically decultured, and significant artefacts are still visible, the amplitude of these perturbations is greatly reduced allowing further filtering and processing procedures a greater chance of defining geological responses. 


\section{Structural Interpretation}

The HiRES magnetic data can be considered as containing a variety of spectral information due to the fine sampling of the acquisition. This allows the data to be considered for two distinct purposes. Firstly, to define magnetic basement characteristics and assign depth estimates to these features and secondly to identify perturbations caused by near surface sedimentary faulting and attempt to map these lineations.

\subsection{Magnetic Basement}

The GSGB data are also well suited for the first task of the deeper structural interpretation due to their inherent long wavelength attributes. A comparison study was undertaken using both existing and modern survey data. An upward continuation of both data sets to $1000 \mathrm{~m}$ ensured they contained a similar spectral aperture warranting a viable comparison.

Structural information in the data sets is examined using the tilt derivative (TDR) as described by Millar and Singh (1994). The tilt derivative or tilt angle is defined as the arctangent of the ratio of a vertical to a combined (total) horizontal derivative:

$$
T D R=\tan ^{-1}\left(\frac{\partial T / \partial z}{\sqrt{(\partial T / \partial x)^{2}+(\partial T / \partial y)^{2}}}\right)
$$

where $\mathrm{T}$ is the magnetic field.

The TDR acts as an Automatic Gain Control (AGC) filter when applied to the field observations and responds equally to both deep and shallow sources. The amplitude range is restricted to the interval $90^{\circ}$ to $-90^{\circ}$ by virtue of the arctangent function and Fairhead et al. (2004) provide examples of utilising the TDR with magnetic field data.

Existing modelling of the TDR response to isolated magnetic bodies (e.g. Fairhead et al. 2004; Verduzco et al. 2004; Salem et al. 2008) indicate that the TDR is positive when over the source, then passes through zero when over (or near) the source edge and is negative outside the source region. Verduzco et al. (2004) note an approximate depth mapping functionality of the TDR in relation to the top of an isolated source region by using the interval between $45^{\circ}$ and $-45^{\circ}$. Here, the zero line defines the edge location, whilst the source depth is roughly equivalent to half the distance between the $45^{\circ}$ and $-45^{\circ}$ contours. 
An additional, and commonly used, scheme for estimating magnetic depth is Euler deconvolution.

Here we use located 3D Euler deconvolution which is based on Euler's homogeneity equation (Thompson 1982; Reid et al. 1990):

$$
\left(x-x_{0}\right) \frac{\partial T}{\partial x}+\left(y-y_{0}\right) \frac{\partial T}{\partial y}+\left(z-z_{0}\right) \frac{\partial T}{\partial z}=-\eta T
$$

where $\eta$ is a measure of the fall-off rate of the magnetic anomaly field $(T)$. The spatial location of a magnetic source $\left(x_{0}, y_{0}, z_{0}\right)$ is then determined from the anomaly field measurements at $(x, y, z)$. Like all methods for estimating magnetic depth idealised sources are used and the adoption of the Euler procedure here is consistent with the recommendations made by Li (2003).

Fig. 5 shows the TDR data contoured at 45 degree intervals alongside the Euler solutions for (a) a subset of the GSGB data and (b) the HiRES data. The results of the two methods (TDR and Euler) display excellent agreement for the separate data sets whilst the correlation between the GSGB and HiRES data is good. The TDR and Euler solutions delineate an equivalent trend in both data sets across the southern Isle of Wight, with the upper extent of the causative body estimated at approximately $2 \mathrm{~km}$ depth. This estimate is obtained using locations where a set of Euler solutions is co-located with the zero contour of the TDR response. We place less confidence in the results across areas where the two sets of results disagree in defining the body edge. It should be noted that the results of the HiRES data suffer from edge artefacts due to the limited size of the survey area particularly in relation to the structural edge in the south. This results in the inappropriate closing of the TDR contours in the SE corner of Fig. 5b.

This depth to magnetic structure, whose lateral extent is well defined by the TDR zero line in the GSGB data, is shallower than the corresponding estimate in Busby and Smith (2001). South of a British National Grid Northing of $45000 \mathrm{~m}$, the source depths for the arcuate but generally E-W trending anomalies appear to be significantly shallower. Both the Euler and TDR solutions suggest volcanic bodies in the upper $1 \mathrm{~km}$ which would place the volcanic rocks within the Permo-Triassic succession and would thus resemble the Exeter volcanics found to the west (Cornwall et al., 1990)

\subsection{Sedimentary features}

The magnetic response of the sedimentary sequence is at the limit of detection for the HiRES survey. In order to improve the limited resolution of the linear trends within the data, grid based data enhancement procedures were undertaken. Spatial derivatives are commonly employed in potential field interpretation as they tend to enhance the resolution of structural edges, making qualitative interpretation less demanding. However, subjecting noisy data to higher order derivatives is known 
to boost the noise component within the data and, due to the significant cultural interference in the Isle of Wight data, only first order derivatives are employed. The approach adopted in this study is to apply a pseudo-gravity transform to the data and from the resultant grid compute the first vertical derivative. The procedure maintains peak amplitudes over the causative bodies but ensures the suppression of the regional trend (Paine, 1986). Lineaments are then interpreted using shaded relief images with illumination provided across a range of inclinations and declinations. Fig. 6 shows an example with illumination from the north. The final line work derived during this study is superimposed on the image with a dashed red line. To limit the influence of cultural artefacts in the interpretation the major urban areas are highlighted in the image. The magnetic data reveals faulting principally orientated in an E-W direction. The major structural discontinuities, the Brixton and Sandown faults, labelled in Fig. 6, are clearly imaged. Between these, within a relay ramp where the Cretaceous succession thickens to the east no evidence of $\mathrm{N}-\mathrm{S}$ faulting is observed.

Fig. 7 shows the HiRES TMI anomaly field following a pseudo-gravity transform with the line work from the magnetic lineament interpretation (red) displayed alongside trends picked from faulting in the Jurassic sequence in the reinterpreted seismic (Evans et al., 2010 'this issue'). The spatial orientation of the mapped faulting is consistent in both data sets with a predominant east-west direction. The lack of depth resolution in the magnetic interpretation makes distinct correlation between equivalent faults unfeasible however the absence of significant N-S orientated faulting in both data sets is a key result.

\section{Conclusions}

This study has aimed to summarise the application of airborne magnetic data to mapping and interpretation of UK geology at scales appropriate to the Isle of Wight. We have utilised existing magnetic baseline data alongside new high resolution airborne data and applied modern interpretation techniques to both.

The methods have examined the magnetic response of both the sedimentary sequence and the basement structure. When focusing on the longer wavelength basement anomalies, we have calculated and compared tilt-depth (TDR) and Euler solutions that have generated equivalent depths to causative bodies. The joint application of these techniques provides a reinforced interpretation of both location and depth to isolated magnetic bodies. The depth estimates obtained in this study suggest that the depths proposed in previous work assessing discrete volcanic bodies to the south of the Isle of Wight should be revised to shallower depths. This would place the bodies within the Permo-Triassic sequence. The depth to the arcuated volcanic body which appears on both the GSGB 
and HiRES surveys, and is mapped beneath the Isle of Wight, is comparable and largely well constrained in both analyses. The depth of the upper surface is estimated to be at a depth of about 2 $\mathrm{km}$.

This study has also assessed an approach for reducing the impact of cultural perturbations by using the analytical signal transform to isolate and remove cultural artefacts. This systematic deculturing has enabled the HiRES data to resolve short wavelength features associated with subtle structural lineaments in the sedimentary sequence. The trend of these lineaments has been compared with subsurface faults mapped from seismic data. The trends in the direction of the lineaments are analogous in the two data sets. 


\section{Acknowledgements}

Our thanks go to Rob Cuss and Peter Hopson for internal reviews and helpful comments. We are also indebted to Mick Lee who provided useful guidance in the improvement of this paper. A newscast of the Isle of Wight airborne geophysical survey is available on the BGS YouTube channel at http://www.youtube.com/watch?v=D4ECcUPNi E , last accessed 01 September 2010. This paper is published with the permission of the Executive Director, British Geological Survey (NERC). 


\section{References}

Beamish, D. and Cuss, R.J., 2009, The HiRES airborne geophysical survey of the Isle of Wight: Logistics Report, British Geological Survey Internal Report, IR/09/54.

Beamish, D. and White, J.C., 2010a, A geological and hydrogeological assessment of the electrical conductivity information from the HiRES airborne geophysical survey of the Isle of Wight, Proceedings of the Geologists' Association, this issue.

Beamish, D. and White, J.C., 2010b, A radiometric airborne geophysical survey of the Isle of Wight, Proceedings of the Geologists' Association, this issue.

British Geological Survey, 1998, Magnetic anomaly map of Britain, Ireland and adjacent areas $(1: 500,000)$ (compilers C.P. Royles and I.F. Smith), British Geological Survey, Keyworth, Nottingham. Busby, J.P. and Smith, N.J.P., 2001, The nature of the Variscan basement in southeast England: evidence from integrated potential field modelling, Geol Mag, 138, 669-685.

Chadwick, R.A., 1993, Aspects of basin inversion in southern Britain, Journal of the Geological Society, 150, 311-322.

Cornwall, J.D., Edwards, R.A., Royles, C.P. and Self, S.J., 1990, Magnetic evidence for the nature and extent of the Exeter lavas, Proceedings of the Ussher Society, 7, 242-245.

Evans et al., 2010, final title required, Proceedings of the Geologists' Association, this issue. Fairhead, J.D., Green, C.M., Verduzco, B. and Mackenzie, C., 2004, A new set of magnetic field derivatives for mapping mineral prospects. ASEG $17^{\text {th }}$ Geophysical Conference and Exhibition, Sydney, Australia, Extended Abstracts.

Hautaniemi, H., Kurimo, M., Multala, J., Leväniemi, H. and Vironmäki, J. 2005. The 'three in one' aerogeophysical concept of GTK in 2004. In: Airo, M-L. (ed.) Aerogeophysics in Finland 1972-2004: Methods, System Characteristics and Applications, Geological Survey of Finland, Special Paper 39, 21-74.

Lahti, M., Beamish, D., Cuss, R.J., and Williams, J., 2007. Deculturing of the Northern Ireland Tellus magnetic data. British Geological Survey Internal Report, IR/07/147.

$\mathrm{Li}, \mathrm{X} ., 2003$. On the use of different methods for estimating magnetic depth, The Leading Edge, 22, 1090-1099. 
Miller, H.G. and Singh, V., 1994, Potential field tilt - A new concept for location of potential field sources, Journal of Applied Geophysics, 32, 213-217.

Paine, J.W., 1986, A comparison of methods for approximating the vertical gradient of one dimensional magnetic field data, Geophysics, 51, 1725-1735.

Reid, A.B., Allsop, J.M., Granser, H., Millet, A.J. and Somerton, I.W., 1990, Magnetic interpretation in three dimensions using Euler deconvolution, Geophysics, 55, 80-91.

Salem, A., Williams, S., Fairhead, J.D., Ravat, D. and Smith, R., 2008, Tilt-depth method: A simple depth estimation method using first order magnetic derivatives, The Leading Edge, 26, 1502-1505.

Thompson, D.T., 1982, EULDPH: A new technique for making compute assisted depth estimates from magnetic data, Geophysics, 47, 31-37.

Underhill, J.R. and Paterson, S., 1998, Genesis of tectonic inversion structures: seismic evidence for the development of key structures along the Purbeck-Isle of Wight Disturbance, Journal of the Geological Society, 155, 975-992.

Verduzco, B., Fairhead, J.D. and Green, C.M., 2004, New insights into magnetic derivatives for structural mapping, The Leading Edge, 23, 116-119.

White, J.C., Beamish, D. and Cuss, R.J., 2009, The HiRES airborne geophysical survey of the Isle of Wight: Processing Report, British Geological Survey Open Report, OR/09/060. 


\section{Figure Captions}

Fig. 1. Top Right: Location map. The extracted region of the GSGB data, approximately defining the Wessex-Channel basin, used for comparison with the HiRES survey. Main image: The GSGB Total Magnetic Intensity (TMI) anomaly data shown with shaded relief using a linear colour scale. The area has dimensions 160 by $136 \mathrm{~km}$ and the shading is from the north. The HiRES Isle of Wight survey area is defined by the small central rectangle and the northern limit of the inner zone of European variscides is labelled $A$.

Fig. 2. The HiRES TMI anomaly data shown as a shaded relief image with linear colour scale. Shading is from the NE. Significant cultural interference masks geologically derived perturbations in the field whilst the regional response of the data is strongly imaged.

Fig. 3. The Analytic Signal (AS) of the HiRES TMI anomaly data as a 3D surface image, looking north. The outline of the Isle of Wight is shown in red whilst peaks in the AS greater than 0.03 $\mathrm{nT} / \mathrm{m}$, corresponding to cultural artefacts, are displayed in blue.

Fig. 4. The de-cultured HiRES TMI anomaly data shown as a shaded relief image with linear colour scale. Shading is from the NE.

Fig. 5. Tilt derivative (TDR) response of the (a) GSGB and (b) HiRES data, after upward continuation to $1000 \mathrm{~m}$ in both cases, shown using a contour interval of 45 degrees. Additional depth estimates derived from 3D Euler solutions are superimposed.

Fig. 6. $1^{\text {st }}$ vertical derivative of the TMI data following a pseudo-gravity transform. Illumination is from the $\mathbf{N}$ and the enclosed polygons denote the major urban areas where cultural disturbance is most pronounced. The dashed red lines display the derived magnetic lineaments with the outline of the Isle of Wight shown in blue. The Brixton Fault (BF) and the Sandown Fault (SF) are labelled accordingly.

Fig. 7. The HiRES TMI anomaly field following a pseudo-gravity transform used as a backdrop to the derived fault orientations from seismic (in blue) and airborne magnetic (in red) data. The major urban areas are defined by hatched polygons. 


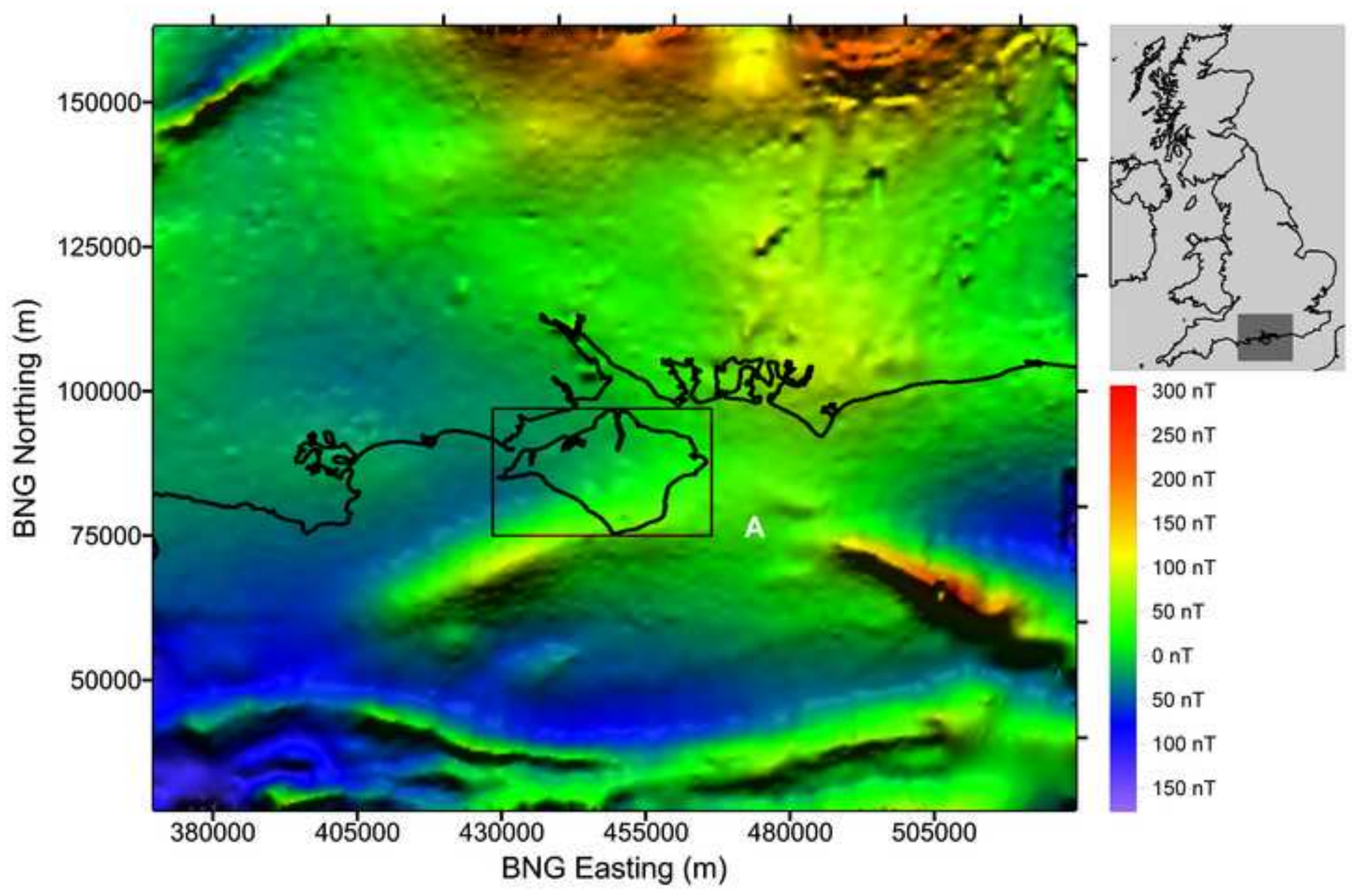


Click here to download high resolution image

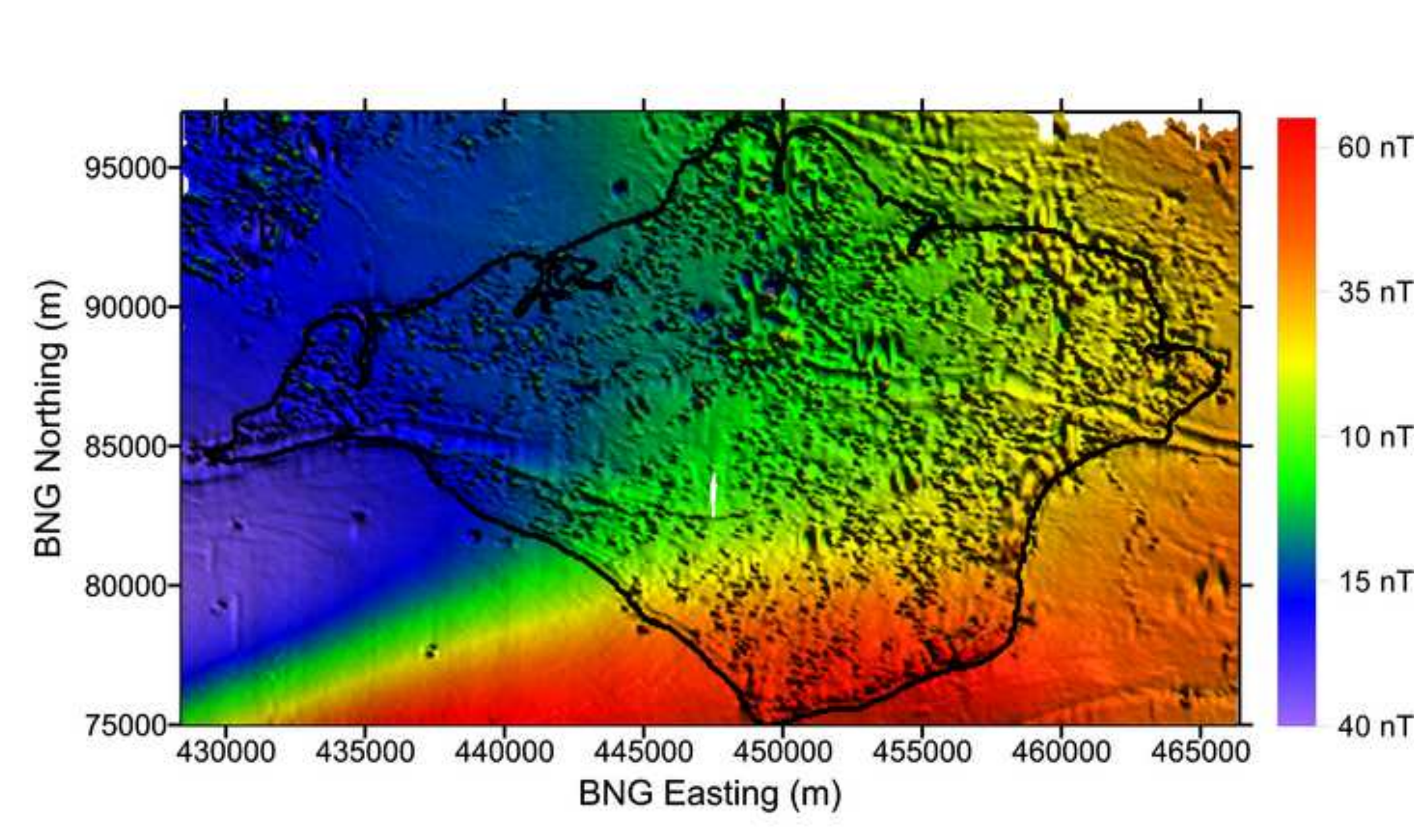

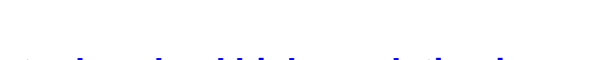

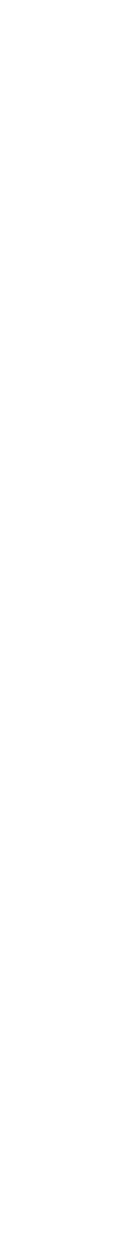


Click here to download high resolution image

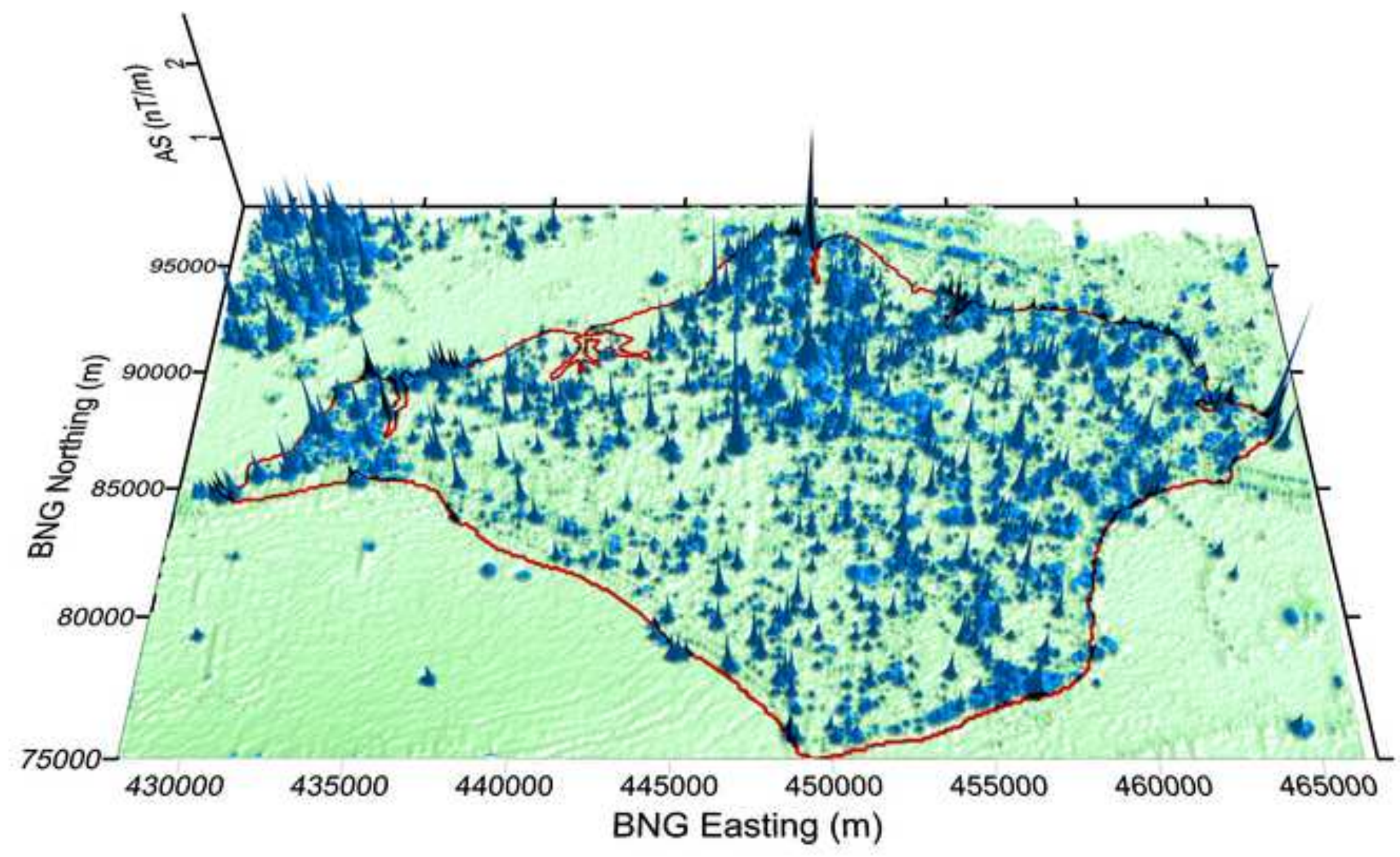


Click here to download high resolution image

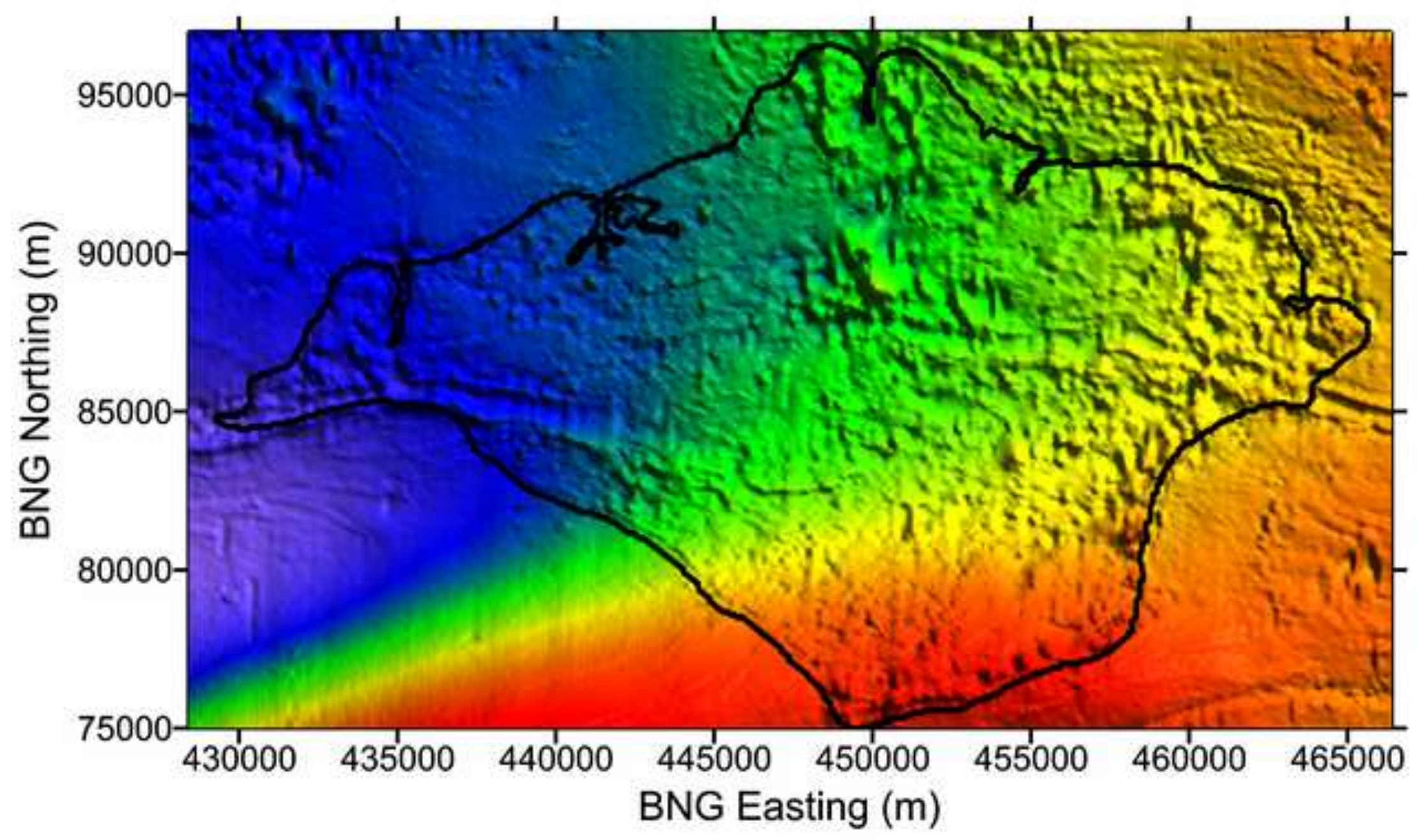

$60 \mathrm{nT}$

$35 \mathrm{nT}$

$10 \mathrm{nT}$

$15 \mathrm{nT}$

$40 \mathrm{nT}$ BNG Easting (m) 
Click here to download high resolution image

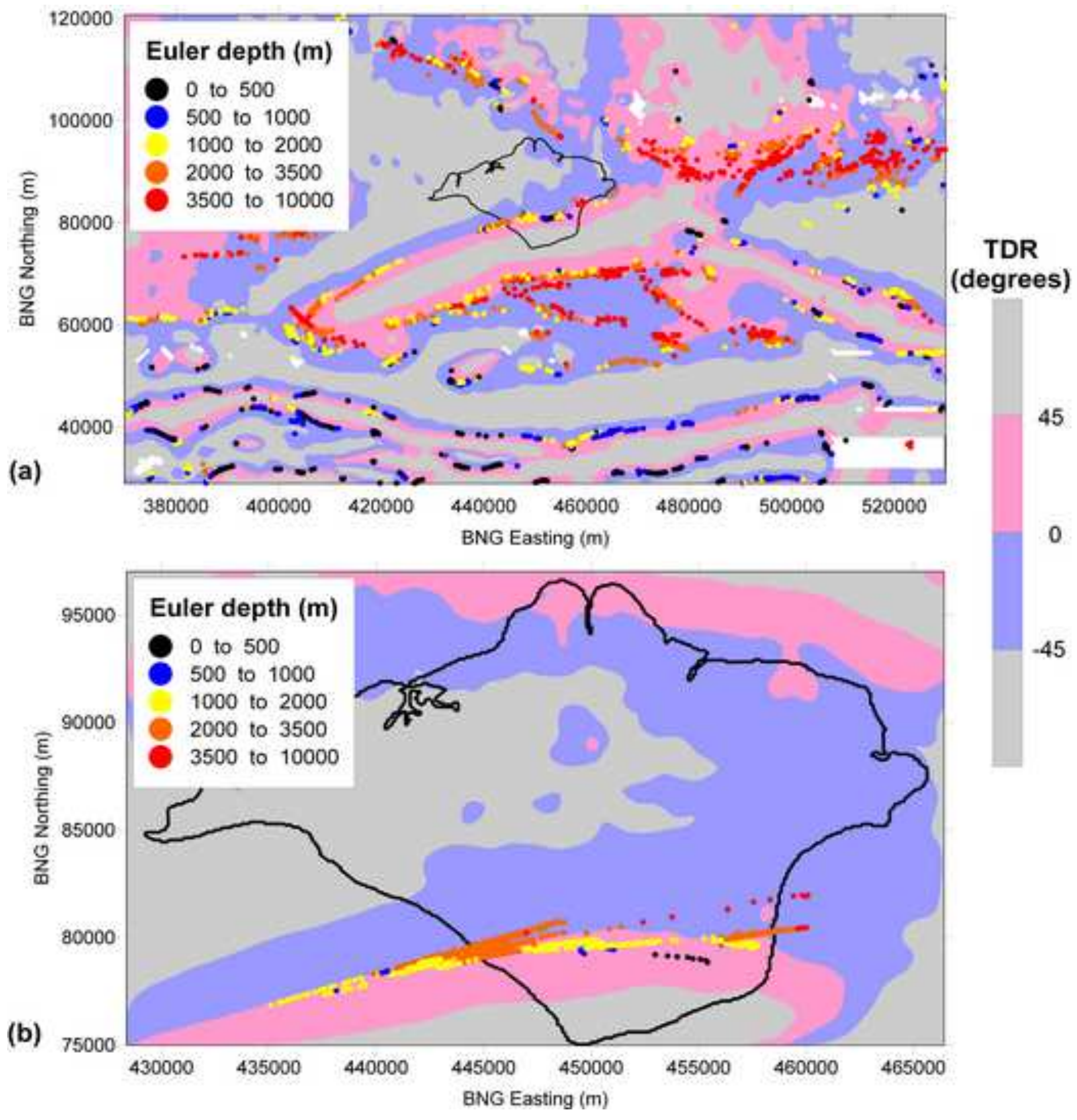




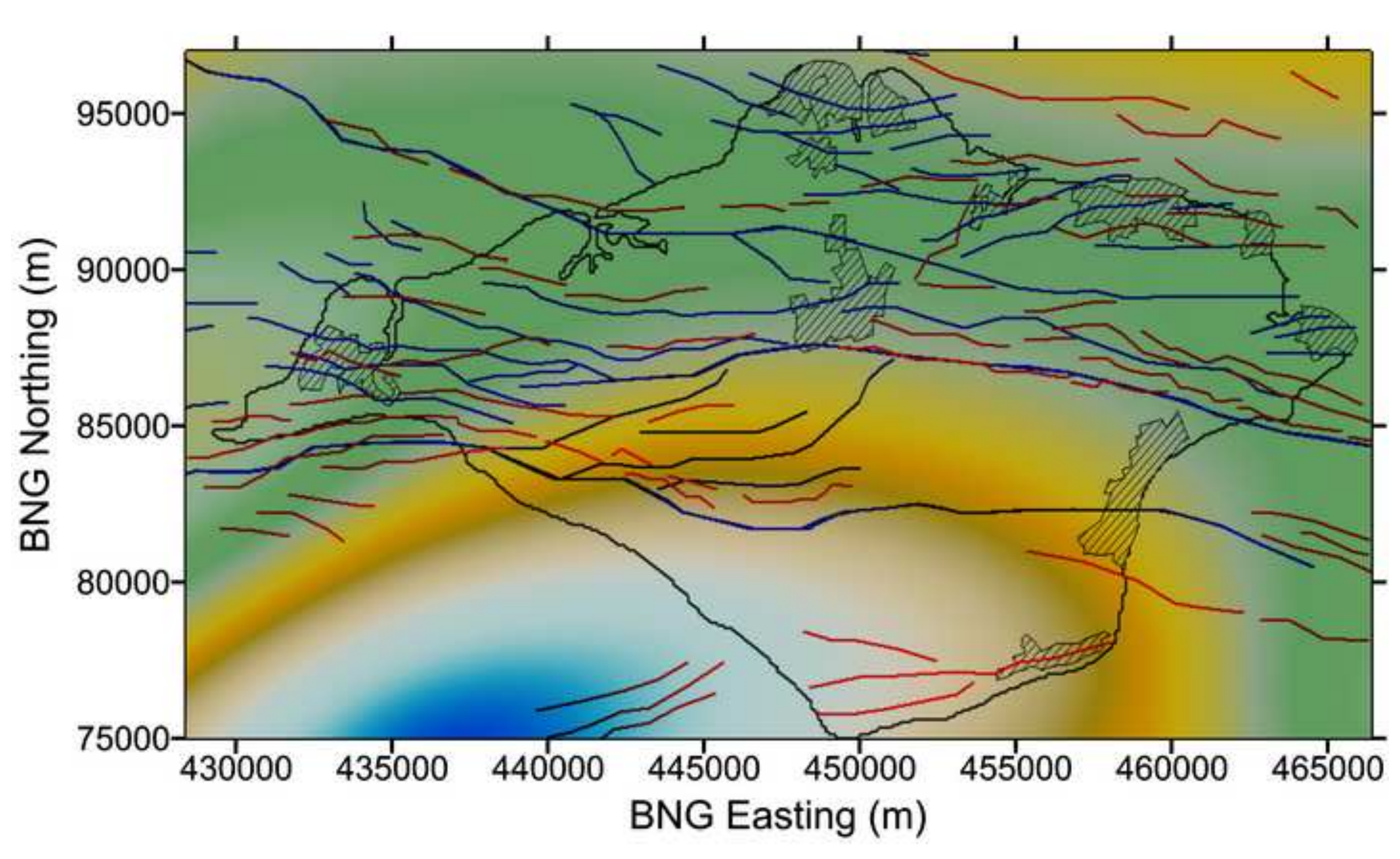

